\title{
IfIISGUC.ORG
}

"İȘ, GÜç" ENDÜSTRi iLIȘKiLERi VE inSAN KAYNAKLARI DERGiSi

"IS, GUC" INDUSTRIAL RELATIONS AND HUMAN RESOURCES JOURNAL

\section{Çalışma Yaşamı Kalitesinin Prosedür Adaleti, İş Tatmini, İş Stresi ve İşten Ayrılma Niyetine Etkisi}

\author{
The Effect Of Work Life Quality On Procedural Justice, Job \\ Satisfaction, Job Stress And Intention To Qunt
}

\author{
Dr. Ömer TURUNÇ \\ Yrd.Doç.Dr.Akif TABAK \\ Harun ŞEŞEN \\ Ali TÜRKYILMAZ \\ Kara Harp Okulu
}

Nisan/April 2010, Cilt/Vol: 12, Say1/Num: 2, Page: 115-134

ISSN: 1303-2860, DOI: 10.4026/1303-2860.2010.146.x

Makalenin on-line kopyasına erişmek için:

http://www.isguc.org/?p=article\&id=415\&vol=12\&num=1\&year=2010

To reach the on-line copy of article:

http://www.isguc.org/?p=article\&id=415\&vol=12\&num=1\&year=2010

Makale İçin İletişim/Correspondence to: 
(C) 2000- 2010

"İşGüç" Endüstri İlişkileri ve İnsan Kaynakları Dergisi

"İşGüç" Industrial Relations and Human Resources Journal

Nisan/April 2010, Cilt/Vol: 12, Say1/Num: 2

ISSN: 1303-2860, DOI: 10.4026/1303-2860.2010.146.x

Editör/Editor-in-Chief

Aşkın Keser (Kocaeli University)

Editör Yardımcıları/Co-Editors

K.Ahmet Sevimli (Uludağ University)

Gözde Yılmaz (Kocaeli University)

Uygulama/Design

Yusuf Budak (Kocaeli Universtiy)

\author{
Yayın Kurulu / Publishing Committee \\ Dr.Zerrin Firat (Uludăg University) \\ Doç.Dr.Aşkın Keser (Kocaeli University) \\ Prof.Dr.Ahmet Selamoğlu (Kocaeli University) \\ Yrd.Doç.Dr.Ahmet Sevimli (Uludağ University) \\ Yrd.Doç.Dr.Abdulkadir Şenkal (Kocaeli University) \\ Yrd.Doç.Dr.Gözde Yilmaz (Kocaeli University) \\ Dr.Memet Zencirkıran (Uludağ University)
}

Uluslararası Danışma Kurulu / International Advisory Board

Prof.Dr.Ronald Burke (York University-Kanada)

Assoc.Prof.Dr.Glenn Dawes (James Cook University-Avustralya)

Prof.Dr.Jan Dul (Erasmus University-Hollanda)

Prof.Dr.Alev Efendioğlu (University of San Francisco-ABD)

Prof.Dr.Adrian Furnham (University College London-İngiltere)

Prof.Dr.Alan Geare (University of Otago- Yeni Zellanda)

Prof.Dr. Ricky Griffin (TAMU-Texas AEM University-ABD)

Assoc. Prof. Dr. Diana Lipinskiene (Kaunos University-Litvanya)

Prof.Dr.George Manning (Northern Kentucky University-ABD)

Prof. Dr. William (L.) Murray (University of San Francisco-ABD)

Prof.Dr.Mustafa Özbilgin (University of East Anglia-UK)

Assoc. Prof. Owen Stanley (James Cook University-Avustralya)

Prof.Dr.Işık Urla Zeytinoğlu (McMaster University-Kanada)

Danışma Kurulu / National Advisory Board

Prof.Dr.Yusuf Alper (Uludağ University)

Prof.Dr.Veysel Bozkurt (Uludağ University)

Prof.Dr.Toker Dereli (Işık University)

Prof.Dr.Nihat Erdoğmuş (Kocaeli University)

Prof.Dr.Ahmet Makal (Ankara University)

Prof.Dr.Ahmet Selamoğlu (Kocaeli University)

Prof.Dr.Nadir Suğur (Anadolu University)

Prof.Dr.Nursel Telman (Maltepe University)

Prof.Dr.Cavide Uyargil (İstanbul University)

Prof.Dr.Engin Yildırım (Sakarya University)

Doç.Dr.Arzu Wasti (Sabancı University)

Dergide yayınlanan yazılardaki görüşler ve bu konudaki sorumluluk yazarlarma aittir.

Yayınlanan eserlerde yer alan tüm içerik kaynak gösterilmeden kullanılamaz.

All the opinions written in articles are under responsibilities of the outhors.

None of the contents published can't be used without being cited. 


\title{
Çalışma Yaşamı Kalitesinin Prosedür Adaleti, İş Tatmini, İş Stresi ve İşten Ayrılma Niyetine Etkisi
}

\author{
The Effect Of Work Life Quality On Procedural Justice, \\ Job Satisfaction, Job Stress And Intention To Quit \\ Dr. Ömer TURUNÇ \\ Yrd.Doç.Dr.Akif TABAK \\ Harun ŞEŞEN \\ Ali TÜRKYILMAZ \\ Kara Harp Okulu
}

\begin{abstract}
Özet:
İnsan faktörü̈ örgütler için önemli bir kritik başarn faktörüdür. Örgütler verimliliklerini arttırmak maksadıyla insan faktörünü yönlendiren her türlü değişkeni optimize etmeye çalışmaktadır. Çalışma yaşamının kalitesinin arttırılması çalışanların verimliliklerini etkileyen örgütsel değişkenlerle ilişkili olduğu düşünülen önemli bir faktördür. Bu bă̆lamda araştırmada, çalışma yaşamı kalitesi (ÇYK) ve bu kavramla ilişkili olduğu düşünülen prosedür adaleti, iş tatmini, iş stresi ve işten ayrlma niyeti ile birlikte bir model oluşturulmuş ve bu modelin üniversite öğretim elemanlarından elde edilen veriye uygunluğu test edilmiştir. Araştırma kapsamında oluşturulan hipotezler ve model uyum testleri, oluşturulan yapısal eşitlik modeli çerçevesinde Kısmi En Küçük Kareler (KEKK) metodu ile analiz edilmiştir. Araştırma sonucunda araştırılan yedi hipotez yazınla uyumlu şekilde kabul edilmiş ve modelin veriye uyumlu olduğu belirlenmiştir.
\end{abstract}

Anahtar Kelimeler: Çalışma Yaşamı Kalitesi, Prosedür adaleti, İş Stresi, İş Tatmini, İşten Ayrılma Niyeti

\begin{abstract}
:
Human factor is important for organizations success. To increase the efficiency organizations try to optimize every variable which affects human factor. Increasing the work life quality which is an important factor for the organizations and related with the other organizational factors, affect efficiency of the workers. In this context, in this study, a model is set up to investigate the the effect of work life quality on procedural justice, job satisfaction, job stress and intention to quit. Data was gathered from university lecturers. The hypotheses was tested with Partial Smallest Squares (PSS) method with structural equation modeling structure. Results showed that the all seven hypotheses was all accepted and model is consistent with the data gathered.
\end{abstract}

Keywords: Work life quality, Procedural justice, Job stres, Job satisfaction, Intention to quit 


\section{Giriş}

Günümüzde organizasyonların (işletmelerin) rekabette üstünlük elde edebilmeleri için insan kaynaklarını etkili kullanmaları gerekmektedir. Organizasyonlarda insan kaynaklarının verimli kullanılabilmesi ise; temel hedefi "üretimde verimlilik olduğu kadar işgörenlerin iş ortamını geliştirmek" (Davis, 1981) de olan çalışma yaşam kalitesi kavramını gündeme getirmektedir. Bu kavram, ilk olarak 1972 yılında Kolombiya üniversitesinde düzenlenen uluslararası işgücü konferansında kullanılmış ve o tarihten bugüne kadar hem tanımı hem de bu kavramin bileşenlerinin ortaya çıkarılmasına yönelik çok sayıda çalışma yapılmıştır.

Çalışma yaşamı kalitesi konusunda geliștirilen tanımlar incelendiğinde; bu tanımların bazılarının çalışanın iş performansını arttırması yönünü, bazılarının çalışanların fiziksel ve psikolojik iyi olma halini koruma yönünü, bazılarının ise iş hayatı ve toplumdaki yabancılaşmayı azaltarak çalıșanların gelişimini sağlaması yönünü vurguladıkları görülmektedir (Huzzard, 2003). Aynı şekilde, bu kavramın bileşenleri incelendiğinde de çalışma yaşamı kalitesinin sekiz bileşenden meydana geldiği görülmektedir. Bu bileşenler; güvenli ve sağlıklı çalışma koşulları, becerileri geliştirme ve kullanma fırsatları, sürekli gelişim ve iyileştirme fırsatları, örgütsel özdeşleşme, organizasyon yasaları, çalışma ve özel yaşam alanı, çalışma yaşamının sosyal boyutu ve adil ücret sistemi (Watson,1975) olarak karşımıza çıkmaktadir.

Çalışanların verimliğinin arttırılmasında en temel unsurlardan olan motivasyon faktörleri konusunda her ne kadar yazında evrensel nitelik taşıyan bazı motivasyon faktörlerinin varlığ 1 kabul edilse bile, Dünyada tüm organizasyonlar için her zaman ve her yerde geçerli olan motivasyon modelinin olmadığ1 görülmektedir(Sabuncuoğlu ve Tüz, 2001; Boyett ve Boyett, 1999). Organizasyonlarda çalışanları motive eden faktörlerin başında bireyin sahip olduğu kişilik özellikleri gelmekte ve bu faktörler bireysel farklılıklardan dolayı değișebilmektedir (Pars ve Şive, 1996; Kovach, 1995; Creech, 1995; Medcof ve Hausdurf, 1995; Lovio-George, 1992). Bu nedenle, örgütsel davranışta motivasyon kapsamında, çalışanların çalışma yaşam kalitesine ilişkin algılamaları ile bu kavramın etkilediği diğer değişkenlerin ortaya çıkarılmasının önemli bir konu olduğu düşünülmektedir. Özellikle bu kavramin, tanım ve bileşenlerinin, örgütsel davranış alanında farklı araştırmalara konu olan örgütsel adalet, iş tatmini, iş stresi ve çalışanların işten ayrılma niyetleri gibi değişkenlerle ilişkili olabileceğini düşündürmektedir. İşte bu çalışmada da çalışanların işten ayrılma niyetleri, iş tatmini, iş stresi, adalet ve çalışma yaşam kalitesi algılamaları arasındaki ilişki ve etkiler, değişkenlerin tamamının yer aldığı bir araştırma modeli çerçevesinde yapılacak yol analizi (path analysis) ile incelenecektir. Böylelikle, tüm değişkenler arasındaki ilişki ve etkilerin yapısal eşitlik modelinde çözümüyle, hem yazına katkıda bulunulabilecek, hem de örgütsel yaşamda çalışan davranışlarını anlama konusunda ipuçları sağlanabilecektir.

\section{2. Çalışma Yaşamı Kalitesi, Prosedür Adaleti, İş Tatmini, İş Stresi ve İşten Ayrılma Niyeti Tutumları Arasındaki İlişki ve Etkiler}

Çalışma yaşamı kalitesi yönetim yazınında son dönemde sıklıkla ele alınan konulardan birisi olarak karşımıza çıkmaktadır. Bu yaklaşımin temelinde yatan düşüncenin, iş tasarımı sırasında örgütü bir bütün olarak düşünmek, görevleri hem insan hem de teknoloji unsuru gözeterek ele almak ve bu durumda gerçekleştirilecek bir örgütsel iklim değişimi ile örgütteki çalışma yaşamı kalitesinin yükseltilmesi olduğu görülmektedir (Özyurda,1994). Davies, Levine ve Taylor'a (1984) göre, çalışma yaşamı kalitesi, örgüt üyelerinin iş ortamındaki yaşam kalitesini artırmaya yönelik tüm beklentileri kapsamaktadır. Günümüzde organizasyonlarda çalışanların yüksek düzeyde çalışma yaşam kalitesi algılamalarının, yüksek düzeyde işgören güdülenmesi ve yüksek düzeyde iş 
tatminine neden olduğu belirtilmektedir (Lawler, 1975). Bu nedenle, organizasyonlarda çalışma yaşam kalitesinin artırılmasına yönelik uygulamaların, organizasyonlara nitelikli işgücünü cezbetmede ve işte bulundurmada önemli bir yeri olduğu görülmektedir (May, Lau ve Johnson, 1999).

Çalışma yaşam kalitesinin organizasyonda çalışan bireylerin adalet algılamalarını da etkileyebileceği söylenebilir. Çünkü kuramsal temelleri Adams'ın $(1963,1965)$ eşitlik teorisine (Equity Theory) kadar uzanan örgütsel adalet algısı(Greenberg, 1990), çalışanların organizasyondaki süreç ve mekanizmaların, görev ve ödüllerin, kendilerine gösterilen davranışların adil olup olmadığ 1 konusunda yargıya ulaşması ve buna göre tutum geliştirmesini kapsamaktadır. Başka bir deyişle, bireyin yüksek düzeyde çalışma yaşam kalitesi algılaması onun örgütsel adalet algılamasını olumlu yönde etkileyebilecektir.

Araştırmacılar tarafından bugüne kadar örgütsel adalet kavramının bileşenlerinin ortaya çıkarılması konusunda çok sayıda çalışma yapılmıştır. Bu çalışmalar sonucunda örgütsel adaletin dağıtım, prosedür, bireylerarası ve bilgisel adalet olmak üzere dört boyuttan meydana geldiği ortaya çıkarılmıştır (Folger ve Konovsky, 1989; Cropanzano ve Greenberg, 1997; Lowe vd., 1995; Chang, 2002; Greenberg, 1987; Collquitt, 2001). Bu boyutlardan prosedür adaletinin, üzerinde en çok çalışılan ve örgütsel süreçler üzerinde de etkili olan bir boyut olduğu söylenebilir. Prosedür adaleti, organizasyonda yönetici tarafından verilen bir kararın, sonucu ne olursa olsun, kontrollü bir süreç sonunda alındığı taktirde adil olarak algılandı ğını ifade etmektedir (Thibaut ve Walker, 1975 aktaran Meydan, 2010, 74). Ayrıca, prosedür adaleti çalışanların gösterdikleri performans karşısında aldıkları ödüllerin neye göre ve nasıl belirlendiğini, ödüllerin dağıtımında kullanılan karar verme süreçlerinin ve süreçlerin çalışanlar tarafından ne derece adil algılandığını açıklayan bir kavramdır (İşbaşı, 2000 aktaran
Meydan, 2010, 74). Bu düşünceler ışığında, araştırmada test edilmek üzere geliştirilen hipotez aşağıdadır;

H1: Çalışma yaşamı kalitesi çalışanların prosedür adaleti algısını pozitif ve anlamlı olarak etkiler.

Günümüzde, bireylerin örgütsel adalet alg1lamalarının onların hem iş tatminleri hem de örgütlerin işleyişinde temel gereksinim olduğu belirtilmektedir( Greenberg, 1990 ‘dan aktaran Meydan 2010). Bu bağlamda, örgütsel adalet algısının da çalışanların iş tatminlerini etkileyeceği düşünülebilir. Araştırmacılar tarafından bu iki değişken arasındaki ilişkiyi ortaya çıkarmaya yönelik yapılan çalışmalarda; prosedür adaletinin, iş tatminini dağıtım adaletine göre daha iyi açıkladığ 1 (Folger ve Konovsky, 1989; Sweeney ve McFarlin,1997) ve prosedür adaleti ile iş tatmini arasında güçlü bir ilişkinin olduğu görülmüştür (Fryxell ve Gordon, 1989; Yoon, 1996). Ayrica bireylerin yüksek düzeyde örgütsel adalet algılamasının bireylerin iş tatmini ve örgütsel bağl1lıklarını olumlu yönde etkilediği de ortaya çıkarılmiştır(Lambert,2007; Roch ve Shanock, 2006 ve Meydan, 2010). Bu düşünceler işığında test edilmek üzere aşağıdaki hipotez geliştirilmiştir.

H2: Prosedür adaleti çalışanların iş tatmini algısını pozitif ve anlamlı olarak etkiler.

Günümüzde iş yaşamında çalışan bireyleri etkileyen konulardan birisi olarak karşımıza, iş stresi çıkmaktadır(Voki ve Bogdani , 2007). Stresin, işe devamsızlık oranlarının artmasina, kazalara, yaralanmalara ve hastalıklara yol açtı ̆̆ 1 bilinmektedir (Sharpley vd., 1996; Ganster ve Schaubroeck, 1991). Bu bağlamda stres, sadece çalışanların sağlığını etkileyen bir sağlık problemi değil; aynı zamanda örgütün işleyişinde bozulmalara da yol açan büyük bir sorun olarak ortaya çıkmaktadır. İş yaşamında strese yol açabilecek faktörler; görevin yapılış şekli, organizasyonun yapısı, fiziksel çevre şartları ve bireyin kendi kişilik özellikleri olarak sıralanmaktadır (Kahya,2006). Organizasyonda çalışan bi- 
reylerin yüksek düzeyde çalışma yaşam kalitesi algılamaları, onların düşük seviyede iş stresi algılamalarına neden olduğuna ilişkin değişik çalışmalar bulunmaktadır. Bu bağlamda, çalışanları çalışma yaşamı kalitesi algılarının iş stresi üzerindeki etkilerini araştırmak amacıyla aşağıdaki hipotez oluşturulmuştur.

H3: Çalışma yaşamı kalitesi, çalışanların iş stresini negatif ve anlamlı olarak etkiler.

Çalışma yaşam kalitesi ile iş tatmini arasında da pozitif yönde bir ilişki ve etkinin olabileceği düşünülmektedir. Çünkü, iş tatmini, iş şartlarının (işin kendisi, yönetimin tutumu) ya da işten elde edilen ücret ve iş güvenliği gibi sonuçların kişisel değerlendirmesi olarak karşımıza çıkmaktadır (Çekmecelioğlu, 2005). Araştırmacılar tarafından bugüne kadar yapılan farklı araştırmalarda, iş tatmininin farklı örgütsel değişkenlerle ilişki ve etkileri ortaya çıkarılmıştır. Örneğin, Arnold ve Feldman (1986) tarafından yapılan çalışmada; ücret, işin kendisi, terfi imkânları, yönetim şekli, çalışma grubu ve çalışma şartları olmak üzere altı temel başlık altında toplanan faktörlerin tamamının çalışanların iş tatminlerini etkilediği sonucuna ulaşılmıştır. Günümüzde çalışma yaşam kalitesinin, iş tatmininden farklı bir olgu olduğu ve ayrıca is tatminini de etkilediği konusunda bir yaklaşım mevcuttur (Quinn ve Shephard, 1974; Davis ve Cherns, 1975; Hackman ve Suttle, 1977; Kabanoff, 1980; Near vd., 1980; Staines, 1980; Kahn, 1981; Lawler, 1982). Bu yaklaşımlar doğrultusunda; iş tatmininin başarılı çalışma yaşam kalitesi çalışmalarıyla ilişkili olduğu (Porter ve arkadaşları, 1974), iş zenginleştirme ve çalışma yaşam kalitesinin, iş alışkanlıkları, örgütsel bağlllık ve özellikle iș tatmini üzerinde etkileri olduğu (Miller ve Monge, 1986; Steers ve Porter, 1983; Walton, 1985) ortaya çıkarılmıştır. Araştırma bulguları ÇYK ile iş tatmini arasında pozitif yönlü ilişki olduğunu ortaya koymaktadır (Fields ve Thacker, 1992). Bu çerçevede, çalışanların çalışma yaşamı kalitesi algılarının iş tatmini üzerindeki etkilerini araştırmak amacıyla oluşturulan hipotez aşağıda veril- miștir.

H4: Çalışma yaşamı kalitesi çalışanların iş tatminini pozitif ve anlamlı olarak etkiler.

İş stresi ile sağlık, hayattan beklentiler, performans, karar verme ve iş tatmini gibi değişkenler arasındaki negatif yöndeki ilişki çok sayıda çalışmada ortaya çıkarılmıştır. (Judge ve Colquitt, 2004; Cicero vd, 2007; Mohr vd., 2007). Örneğin ambulans ve acil müdahale teknisyenlerinde(Young ve Couper, 1995), tabiplerde(Williams vd., 2001), hemşirelerde(Tetrick ve LaRocco, 1987) ve satış personelinde (Babakus vd, 1999) değişik dönemlerde yapılan araştırmalarda, iş tatmini ile iş stresi arasında ters yönlü ilişki olduğu ortaya çıkarılmıştır. Bu iki değişken arasında yapılan meta analiz çalışmalarında da negatif yönlü ilişki rapor edilmiştir (Jackson ve Schuler, 1985; Daniels ve Bailey, 1999). Görüldüğ ü üzere, yapılan çalışmalar incelendiğinde, iş stresi ile iş tatmini arasında yakın bir ilişkinin olduğu ve iş stresinin iş tatminsizliğine neden olduğu şeklindedir. Bu düşünceler 1şı̆̆ında, test edilmek üzere geliştirilen hipotez aşağıdadir:

H5: İş stresi çalışanların iş tatminini negatif ve anlamlı olarak etkiler.

Çalışmada ele alınacak değişkenlerden birisi olan işten ayrılma niyeti, bir ücret karşılığ çalışan bireyin gönüllü olarak işi bırakmaya niyetlenmesi olarak tanımlanmaktadır (Hom ve Griffeth, 1995: 4). Bu güne kadar yapilan çalışmalarda çalışanların işten ayrılmaları niyetlerine artıran nedenlerin verimlilik, etkililik ve kazançların azalmasıyla ilişkili olduğu ortaya çıkarılmıştır(Larkin, 1995; Roth ve Roth, 1995). Ayrıca, çalışma yaşam kalitesinin, işten ayrilma niyetiyle negatif yönde ilişkili olduğu ve yüksek ücret ve çalışanlara sağlanan faydaların İAN ile ilişkili olduğu belirtilmektedir (Shaw, Delery, Jenkins, ve Gupta, 1998). Aynı şekilde çok sayıda çalışmada stres ile işten ayrılma niyeti arasında ise pozitif yönlü bir ilişki olduğu ortaya çıkarılmıştır(Kemery vd., 1985; Matteson ve Ivancevich ,1987; Tuten ve Neidermeyer, 
2004).Buna göre, çalışanların iş yerinde yaşadıkları stres seviyesi arttıkça, işten ayrılma niyetleri de artmakta, sonuç olarak yaşanılan stres birey açısından baş edilemeyecek düzeye geldiğinde ya da daha az stresli bir alternatif oluştuğunda çalışan işten ayrılmaktadır. Bu bağlamda test edilmek üzere geliştirilen hipotezler aşağıda verilmiştir.

H6: İş tatmini çalışanların İAN'ni negatif ve anlaml olarak etkiler.

H7: İş stresi çalışanların İAN'ni pozitif ve anlamlı olarak etkiler.

Günümüzde organizasyonlarda çalışanların etkiliği ve verimliliğinin artırılması için farklı örgütsel değişkenler arasındaki ilişki ve etkilerini ortaya çıkarılmasına yönelik araştırmalar yapıldığı görülmektedir. Bu araştırmalarda çalışma yaşam kalitesi, örgütsel adalet, iş stresi, iş tatmini ve işten ayrılma niyeti gibi örgütsel değişkenlerin de sıkça kullanıldığı görülmektedir. Ancak ülkemizde bu beş değişkenin tamamının birlikte ele alındığı araştırmaya rastlanmamıştır. Bu nedenle çalışmada, teorik ve görgül çalışmalar esas alınarak oluşturulan hipotezlerden yola çıkılarak Şekil-1'de yer alan araştırma modeli geliştirilmiştir.

\section{Yöntem}

\subsection{Araştırmanın Örneklemi}

Araştırmanın ana kütlesini kamuya ait bir üniversitede çalışan öğretim üyeleri oluşturmaktadır. Bu üniversitede öğretim üyesi olarak toplam 224 kişi çalışmaktadır. Bu kapsamda kümelere göre örnekleme yöntemiyle tesadüfi olarak seçilen toplam $175 \mathrm{ki}$ şiye anket uygulaması yapılması planlanmıştır. Gönderilen anketlerden 132'si geri dönmüş, 106 tanesi analiz yapmak için uygun bulunmuştur. Katılımcıların yaşları 23 ile 45 arasında değişmekte olup, yaş ortalaması 34,31 (SS=4,04); kurumda çalışma süreleri ise 1-24 yıl arasında değişmekte ve ortalama $12,09(\mathrm{SS}=4,82)$ yıldır. Araştırmaya katılan öğretim elemanlarının \%34'ü kadın, $\% 66$ 's1 ise erkektir.

\subsection{Araştırmanın Ölçekleri}

Çalışanların çalışma yaşamı kalitesi algılarının, iş stresi, iş tatmini ve işten ayrılma niyeti düzeylerine etkisini belirlemek amaciyla araştırmada kullanılan ölçeklere ilişkin bilgiler aşağıda verilmektedir. Araştırmada oluşturulan modelleri ve hipotezleri test etmek amaciyla gözlenen değişkenlerle yol analizi yapılmıştır. Gözlenen değişkenlerle yol analizi yapmak için modeldeki değişkenlerin ölçülmesinde kullanılan bütün ölçüm araçlarının geçerli ve güvenilir olması gerekmektedir (Şimşek, 2007: 19). Bu amaçla, araştırmada kullanılan bütün ölçeklere ilişkin yapılan geçerlilik ve güvenirlilik çalışmalarına ilişkin sonuçlar, her ölçekle ilgili bölümün sonunda verilmiştir. 


\subsection{1. Çalışma Yaşamı Kalitesi Ölçeği}

Çalışanların çalışma yaşamı kalitesi algılarını ölçmek üzere Sirgy vd. (2001)'nin geliştirdiği ölçek kullanılmıştır. Ölçek Küçükusta (2007) tarafından konaklama işletmelerinde geliştirilerek uygulanmış ve bu çalışmada ölçek güvenilirliği 0,857 olarak bildirilmiştir. Yedi maddeden oluşan ölçek tek boyutludur. Cevaplar 5'li likert (1=Kesinlikle katılmiyorum, 5=Kesinlikle katılıyorum) ölçeği ile alınmıştır.

Ölçeğin yapı geçerliliğini test etmek maksadıyla doğrulayıcı faktör analizi yapılmıştır. Faktör analizi sonucunda verilerin ölçeğin tek faktörlü yapısına uyum sağladığ 1 ve faktör yüklerinin de .73 ile .83 arasında olduğu tespit edilmiştir. Faktör yüklenmesi düşük olan iki madde analizden çıkarılmıştır. Yapılan güvenirlik analizi sonucunda ölçeğin Cronbach alfa güvenirlik katsayısı .84 olarak bulunmuştur.

\subsubsection{Prosedür Adaleti Ölçeğ}

Prosedür adaletinin ölçülmesinde Niehoff ve Moorman (1993) tarafından geliştirilen ve Gürpınar (2006) tarafından Türkçeye uyarlanan işlem adaleti ölçeği kullanılmıştır. Cevaplar 5'li likert (1=Kesinlikle katılmam, $5=$ Kesinlikle katılırım) ölçeği ile alınmıştır. Ölçek 15 maddeden oluşmakta olup ilk 6 madde posedür adaletine, diğer 10 madde ise informatik prosedür adaletine yönelik soruları içermektedir. Ölçeğin orijinalinin güvenirlik katsayısı .85 ile .98' tir (Moorman, 1991; Niehoff ve Moorman , 1993). Ölçeğin Türkiye'deki güvenilirliği Özdevecioğlu (2003) tarafından .79, Gürpınar (2006) tarafından .96 olarak belirlenmiştir.

Araştırmada 6 maddeli prosedür adaleti ölçeği kullanılmıştır. Doğrulayıcı faktör analizi sonucunda ölçeğin tek faktörlü yapısı doğrulanmiş olup, faktör yükleri .77 ile .91 arasında değişmektedir. Faktör yüklenmesi düşük olan bir madde analizden çıkarılmıştır. Güvenirlik analizi sonucunda Cronbach alfa güvenirlik katsayısı .90 olarak tespit edilmiştir.

\subsection{3. İş Stresi Ölçeği}

Çalışanlarda algılanan stresi ölçmek üzere Cohen, Kamarck ve Mermelstein (1983) tarafından geliştirilen ölçek kullanılmıştır. Dört maddeden oluşan ve tek boyutlu olan ölçek Küçükusta (2007) tarafından konaklama işletmelerinde uygulanmış ve bu çalışmada ölçek güvenilirliği .76 olarak bildirilmiştir. Cevaplar 5'li likert (1=Kesinlikle katılmıyorum, 5=Kesinlikle katılıyorum) ölçeği ile alınmıştır.

Doğrulayıcı faktör analizi sonucunda ölçeğin tek faktörlü yapısı doğrulanmış olup, faktör yükleri .83 ile .92 arasında değişmektedir. Güvenirlik analizi sonucunda Cronbach alfa güvenirlik katsayısı .91 olarak tespit edilmiştir.

\subsection{4. İş Tatmini Ölçeği}

İş tatmininin ölçülmesi için; Weis ve arkadaşları (1967) tarafından geliştirilen ve Oran (1989) tarafından Türkçeye uyarlanan Minnesota İş Tatmini Anketi (Minnesota Satisfaction Questionnaire) kullanılmıştır. Cevaplar 5'li likert (1=Hiç tatmin etmiyor, $5=$ Çok tatmin ediyor) ölçeği ile alınmıştır. Ölçeğin orijinalinin güvenirlik katsayısı .83' tür (Moorman, 1993). Ölçek 20 maddeden oluşmakta olup Türkiye'deki güvenirlik çalışması Yıldırım (1996) tarafından yapılmış, test-tekrar test güvenirlik katsayısı .76, iç tutarlılık katsayısı .90 olarak bulunmuştur.

Ölçeğin yapı geçerliliğini test etmek maksadıyla doğrulayıcı faktör analizi yapılmıştır. Faktör analizi sonucunda verilerin ölçeğin iki faktörlü yapısına uyum sağlamadığı belirlenmiştir. Bu nedenle ölçekte dişsal tatmine yönelik boyut olarak adlandırılan 8 maddeli boyut çalışmaya dahil edilmiştir. Bu boyutta doğrulayıc faktör analizi sonucunda faktör yüklerinin de .72 ile .87 arasında olduğu tespit edilmiştir. Faktör yüklenmesi düşük olan bir madde analizden çıkarılmıştır. Yapılan güvenirlik analizi sonucunda ölçeğin Cronbach alfa güvenirlik katsayısı .89 olarak bulunmuştur. 


\subsection{5. İsten Ayrılma Niveti Ölceği}

Çalışmada yer alan İşten Ayrılma Eğilimi ölçeği Wayne, Shore ve Linden (1997) tarafından geliştirilmiştir. Bu ölçekte işten ayrılma eğilimi üç ifade ile ölçülmekte olup ölçek tek boyutludur. Küçükusta (2007) tarafından konaklama işletmelerinde uygulanmış ve bu çalışmada ölçek güvenilirliği 0,69 olarak bildirilmiştir. Cevaplar 5'li likert (1=Kesinlikle katılmıyorum, 5=Kesinlikle katılıyorum) ölçeği ile alınmıştır.

Doğrulayıcı faktör analizi sonucunda ölçeğin tek faktörlü yapısı doğrulanmış olup, faktör yükleri .83 ile .93 arasında değişmektedir. Güvenirlik analizi sonucunda Cronbach alfa güvenirlik katsayısı .87 olarak tespit edilmiştir.

\section{Bulgular}

\subsection{Yapısal Eşitlik Modelinin KEKK Me- todu ile Tahmini}

Yapısal Eşitlik Modelleri (YEM), sürekli ya da kesikli bir gurup bağımsız değişkenin, bir ya da daha fazla sürekli ya da kesikli değişkenlerle arasındaki ilişkilerin incelenebilmesine imkan sağlayan istatistik modelleme metodudur. YEM'ler, gizli değişkenleri (tatmin, kalite, performans, vs.), bu gizli değişkenleri açıklayan ölçüm değişkenlerini ve bunların ilişkilerini sistematik şekilde modelleyebilen tekniklerdir. Yapısal eşitlik modellerinin amac1, giriş verilerindeki değişikliğe göre elde edilecek sonuçların değişimini doğru olarak ifade edebilen bir denklem modeli oluşturabilmektir. Yapısal eşitlik modelleri, çoklu regresyon ve faktör analizinin kombinasyonudur (Gefen vd., 2000).

Yapısal eşitlik modellerinin tahmininde yaygin olarak kullanılan iki yöntem mevcuttur. En fazla bilinen yapısal eşitlik modeli kovaryans tabanlı metodlardır (Bollen, 1989; Rigdon, 1998). Kovaryans tabanlı metod, kullanılan bilgisayar programindan dolay LISREL metodu olarak da adlandırılır. Diğer yöntem ise varyans tabanlı Kısmi En Küçük Kareler (KEKK) metodudur (Wold, 1985).
Bu iki yöntem; analizlerin amacı, sahip oldukları istatistik varsayımlar ve ürettikleri uygunluk istatistikleri bakımından birbirlerinden farklılık gösterirler (Gefen vd., 2002). KEKK metodunun amacı genel olarak yüksek R-kare ve anlamlı $t$ değerlerine sahip bir ilişki modelini tahmin edebilmektir (Chin, 1998; Fornell ve Bookstein, 1982). Bunun yaninda, kovaryans tabanlı LISREL metodunun amacı ise; modelde belirlenen tüm ilişkilerin kabul edilebilir, önerilen teorinin doğrulanabilir ve veri setiyle uyumlu olduğunu göstermektir (Bollen, 1989). LISREL metodu YEM uygulamalarında sık kullanılmasına rağmen, KEKK modelinin LISREL'e göre üstün olduğu bazı yönler mevcuttur. Yönetim bilimi üzerin yapılan araştırmalarda toplanan veriler genelde kişisel değerlendirmelerin sonuçları olduğundan tam bir kesinlik göstermezler ve istenen bir dağılıma uymayabilirler. Bazı durumlarda da yeteri kadar çok veri toplamak mümkün olmayabilir. Bu tür durumlarda LISREL sağlıklı sonuçlar üretememektedir. Ancak KEKK yöntemi az sayıda veri, kesikli ve sürekli çok sayıda değişkenle de çalışmaktadır. KEKK metodunun uygulanması için verilerin dağllımı önemli değildir. LISREL yöntemi teorik çalışmalar için, KEKK metodu ise pratik uygulamalar için daha uygundur (Chin, 1998). İki yöntem arasında, destekledikleri ilişki türü açısından da fark vardır. KEKK metodu reflektif ve formatif yapılandırılmış bloklar için uygundur. Ancak LISREL sadece reflektif bloklar için kullanılmaktadır (Chin, 1998; Fornell ve Bookstein, 1982).

Yukarıda bahsedilen avantajlarına ek olarak, kullanım kolaylığı da göz önünde bulundurulduğunda bu çalışmadaki modelin tahmininde KEKK metodu kullanilması kararlaştırılmıştır. Şekil 1'de verilen modeldeki gizli değişkenler ve onların ölçüm değişkenleri Tablo 1'de sunulmuştur.

\subsection{Doğrulayıcı Faktör Analizi}

Doğrulayıcı faktör analizi, bloğu oluşturan ölçüm değişkenlerinin aynı faktörü ölçtüklerini test etmektedir (Hulland, 1999). Blok- 
Tablo 1

Yapısal Model Değişkenleri

\begin{tabular}{|c|c|c|}
\hline $\begin{array}{c}\text { Gizli } \\
\text { Deăisken }\end{array}$ & \multicolumn{2}{|c|}{ Ölçüm Değişkeni } \\
\hline $\begin{array}{l}\text { ÇYK } \\
\text { Çalışma } \\
\text { Yaşam } \\
\text { Kalitesi }\end{array}$ & $\begin{array}{l}\text { ÇYK1 } \\
\text { ÇKY2 } \\
\text { ÇYK3 } \\
\text { ÇYK4 } \\
\text { ÇYK5 }\end{array}$ & $\begin{array}{l}\text { : İşin, potansiyeli fark etmeye olanak tanıması } \\
\text { İssyerinde saygı görme } \\
\text { : İşin yaratıcılığı geliştirmeye yardımcı olması } \\
\text { : İşin yaratıcılılık gerektirmesi } \\
\text { : İşyerinde takdir edilme }\end{array}$ \\
\hline $\begin{array}{l}\text { PRA } \\
\text { Prosedür } \\
\text { Adaleti }\end{array}$ & $\begin{array}{l}\text { PRA1 } \\
\text { PRA2 } \\
\text { PRA3 } \\
\text { PRA4 } \\
\text { PRA5 }\end{array}$ & $\begin{array}{l}\text { : Amirin kararlarında tarafsız olması } \\
\text { : Amirin, işle ilgili kararları öncesi çalışanların tereddütlerini dinlemesi. } \\
\text { : Amirin kararla ilgili gerekli bilgileri toplaması. } \\
\text { : Amirin, verilen kararları açıklamak için gerektiğinde ek bilgi sağlaması. } \\
\text { : İşle ilgili verilen kararların tutarlı bir şekilde etkilenen tüm çalışanlara uygulanması. }\end{array}$ \\
\hline $\begin{array}{c}\text { ISS } \\
\text { İş Stresi }\end{array}$ & $\begin{array}{l}\text { İS1 } \\
\text { İS2 } \\
\text { İS3 } \\
\text { İS4 }\end{array}$ & $\begin{array}{l}\text { : Kişisel sorunları çözümleyebilme } \\
\text { : Zorluklar ile baş edebilme } \\
\text { : İşlerin yolunda gitmemesi } \\
\text { : Yaşamdaki olayları kontrol edememe }\end{array}$ \\
\hline $\begin{array}{c}\text { İT } \\
\text { İş Tatmini }\end{array}$ & $\begin{array}{l}\text { İT1 } \\
\text { İT2 } \\
\text { İT3 } \\
\text { İT4 } \\
\text { İT5 } \\
\text { İT6 }\end{array}$ & $\begin{array}{l}\text { :Yapılan iç ve alınan ücret } \\
\text { : Kendi kararlarını uygulayabilme } \\
\text { : Kendi yöntemlerini kullanabilme } \\
\text { : Çalışma koşulları } \\
\text { : Takdir edilme } \\
\text { :Yapılan iş karşılığında başarı }\end{array}$ \\
\hline $\begin{array}{c}\text { IAN } \\
\text { İşten Ayrılma } \\
\text { Niyeti }\end{array}$ & $\begin{array}{l}\text { İAN1 } \\
\text { İAN2 } \\
\text { İAN3 }\end{array}$ & $\begin{array}{l}\text { : İşi bırakmayı düşünme. } \\
\text { : Daha iyi bir iş bunduğunda işten ayrılma isteği. } \\
\text { : Sıklıkla işten ayrılmayı düşünme. }\end{array}$ \\
\hline
\end{tabular}

ların tek boyutluluğu Cronbach alfa, DillonGoldstein $\rho$ we ana bileşenler analizi (principal component analysis) ile test edilmektedir (Tenenhaus vd., 2005).

Tablo 2'de çalışmada ölçülen tüm blokların Cronbach alfa ve Dillon-Goldstein $\rho$ değerleri ve ana bileşenler analizi sonuçları verilmiştir. Cronbach alfa ve Dillon-Goldstein $\rho$ değerleri 0.80'nin üzerinde bulunmuştur. Sonuçların 0.70'in üzerinde olması tek boyutluluk göstergesidir. Bloklar için ayrı ayrı uygulanan ana bileşenler analizi sonuçlarryla beraber (ilk özdeğer $>1$ ve 2 . özdeğer $<$ 1) tüm testler blokların tek boyutlu olduklarını, yani her bloktaki değişkenlerin bir ve aynı faktörü ölçtüklerini göstermektedir.

Tablo 2

Doğrulayıcı Faktör Analizi Sonuçları

\begin{tabular}{|l|c|c|c|c|c|}
\hline Blok & $\begin{array}{c}\text { Gözlem } \\
\text { Değişkeni }\end{array}$ & $\begin{array}{c}\text { Cronbach } \\
\text { Alpha }\end{array}$ & $\begin{array}{c}\text { Dillon-Goldstein } \\
\text { rho }\end{array}$ & 1. Özdeğer & 2. Özdeğer \\
\hline ÇYK & 5 & 0,8454 & 0,8919 & 2,8960 & 0,6573 \\
\hline İS & 4 & 0,9150 & 0,9409 & 3,9278 & 0,4722 \\
\hline İAN & 3 & 0,8786 & 0,9265 & 3,3714 & 0,5435 \\
\hline ÍT & 6 & 0,8860 & 0,9137 & 4,5017 & 0,8842 \\
\hline PRA & 5 & 0,9013 & 0,9285 & 4,2987 & 0,5650 \\
\hline
\end{tabular}


KEKK metodu, modeldeki parametrelerin hesaplanabilmesi için iki aşamalı bir tahmin algoritması kullanır:

1. Dış modelin (Ölçüm Modeli) tahmini: Gözlem değişkenleri ve gizli değişkenler arasındaki ilişkilerin tahmin edilmesi amacıyla uygulanan iteratif hesaplama.

$$
Y_{j}=\sum \widetilde{w}_{j h}\left(x_{j h}-\bar{x}_{j h}\right)
$$

Y gizli değişkenin dış model hesabı, w ölçüm değişkeni ve bağlı olduğu gizli değişken arasındaki ilişki katsayısı, x gözlemlenen değişkenin değeri.

2. İç modelin (Yapısal Model) tahmini: Gizli değişkenlerin değerleri ve gizli değişkenler arasındaki ilişki değerlerinin hesaplanabilmesi amaçlı basit ya da çoklu regresyon modeli.

$$
Z_{j}=\sum \mathrm{e}_{\mathrm{ji}} Y_{i}
$$

Z gizli değişkenin değeri, e gizli değişkenler arası ilişki katsayısı.

Matlab programinda 8 iterasyon sonucunda bulunan modelin diş model tahmin sonuçları; dış model ağırlıkları, yüklemeler (loadings) ve komunaliti değerleri Tablo 3'de verilmiştir.

Yapısal eşitlik modelinin genel kullanılabilirliği modelin güvenilirlik ve geçerlilik test sonuçlarına bağlıdır. KEKK modelinde bir maddenin (değişken) güvenilirliği (individual item reliability), ölçüm değişkeni ile gizli değişken arasındaki yüklemenin değeriyle ölçülür. Genel kabul gören kurala göre ölçüm değişkeni ve bağlı olduğu gizli değişken arasındaki yükleme değerinin 0.70 'den yüksek olması gerekmektedir. Bu sonuç bloğun o ölçüm değişkeni ile paylaştığ1 varyansin $\% 50$ 'den yüksek olduğunu gösterir ve hata ile paylaşılan varyanstan daha yüksek olması anlamina gelir (Hulland, 1999).

Ölçüm modelinde bulunan sonuçlara göre gizli değişkenler ve onların ölçüm değişkenleri arasındaki yüklemelerin oldukça yüksek ve pozitif olduğu gözükmektedir. Tüm yüklemeler 0.70 'den büyüktür. Reflektif bir bloğun yakınsaklık geçerliliği (convergent validity) bloktaki ölçüm değişkenlerinin komunaliti değerlerinin ortalaması kullanılarak ölçülebilir (average variance extracted) (Hulland, 1999). Komunaliti değeri bir blokla o bloğa bağlı olan ölçüm değişkeni arasındaki paylaşılan varyansı ölçer. Bir bloğun yakınsaklık geçerliliğinin olabilmesi için

\section{Tablo 3}

Dış model sonuçları

\begin{tabular}{|l|c|c|c|}
\hline $\begin{array}{l}\text { Ölçüm } \\
\text { Değişkeni }\end{array}$ & $\begin{array}{c}\text { Diş } \\
\text { Ăılık }\end{array}$ & Yükleme & Komunaliti \\
\hline ÇYK2 & 0,2210 & 0,7329 & 0,5371 \\
\hline ÇYK4 & 0,2894 & 0,8390 & 0,7040 \\
\hline ÇYK5 & 0,2516 & 0,7843 & 0,6151 \\
\hline ÇYK6 & 0,3138 & 0,8319 & 0,6921 \\
\hline ÇYK7 & 0,2379 & 0,7463 & 0,5570 \\
\hline İS1 & 0,2245 & 0,9014 & 0,8126 \\
\hline İS2 & 0,2401 & 0,8370 & 0,7005 \\
\hline İS3 & 0,2798 & 0,9206 & 0,8475 \\
\hline İS4 & 0,2635 & 0,9087 & 0,8257 \\
\hline İAN1 & 0,2789 & 0,8308 & 0,6902 \\
\hline İAN2 & 0,3283 & 0,9220 & 0,8501 \\
\hline İAN3 & 0,3333 & 0,9342 & 0,8727 \\
\hline İT3 & 0,1801 & 0,7294 & 0,5320 \\
\hline İT15 & 0,2183 & 0,8769 & 0,7690 \\
\hline İT16 & 0,1813 & 0,8222 & 0,6760 \\
\hline İT17 & 0,1792 & 0,7827 & 0,6127 \\
\hline İT19 & 0,2076 & 0,8074 & 0,6519 \\
\hline İT20 & 0,1853 & 0,7737 & 0,5986 \\
\hline ÖA6 & 0,2365 & 0,8494 & 0,7214 \\
\hline ÖA7 & 0,2744 & 0,9151 & 0,8375 \\
\hline ÖA8 & 0,1837 & 0,8285 & 0,6864 \\
\hline ÖA9 & 0,1206 & 0,7724 & 0,5966 \\
\hline ÖA10 & 0,2423 & 0,8524 & 0,7266 \\
\hline
\end{tabular}


ortalama komunaliti değeri en azından 0.50 veya üstünde olması gerekir. Bu değer bir bloktaki değişimin \%50 den daha fazlasının model değişkenleri tarafından açıklanabildiği anlamına gelir. Bu çalışmada ortalama komunaliti değerleri Çalışma Yaşam Kalitesi (ÇYK) bloğu için 0.62, İş Stresi (IS) için 0.79, İş Tatmini (İT) için 0.64, Prosedür Adaleti (PRA) için 0.71 ve İşten Ayrılma Niyeti (İAN) için 0.80 bulunmuştur. Modelin asıl amacı çalışanların işten ayrılma niyetlerini ölçmek olduğundan, İAN'deki değişimin \%80'inin model değișkenleri tarafından açıklanabiliyor olması, modelin geçerliliğini göstermektedir.

Teorik model kurulurken beş gizli değişkenin teorik olarak birbirinden farklı kavramları ölçtüğü şeklinde kurulmuştur. Bloğun diğer bloklardan farklı bir kavramı ölçtügünü kontrol etmek için ayırdedicilik geçerliliğini (discriminant validity) hesaplamak gerekir. Bir bloğun ayırdedicilik geçerliliği o bloğun kendi değişkenleriyle paylaşılan ortalama varyansin (ortalama komunaliti), diğer bloklarla paylaşılan varyanstan daha yüksek olmasıyla sağlanabilir.

Tablo 4'de köşegen elemanları (koyu) ortalama komunaliti değerleri ve diğer değerler ise bloklar arası korelasyon sonuçlarıdır. Sonuçlar tüm blokların kavramsal olarak ve ampirik olarak birbirlerinden farklı olduklarını göstermektedir.

Dış model tahminindeki önemli sonuçlardan biri de ölçüm değişkenlerinin gizli değişkenle aralarındaki ilişki katsayısıdır (dış ağırlık). Tüm değişkenlerin diş ağırlık degerleri de Tablo 3'de verilmiştir. Bu değerler o bloğu oluşturan değişkenlerin önem derecelerini ifade etmektedir.

Önerilen yapısal denklik modelinin güvenilirlik ve geçerlilik analizlerini yaptıktan sonra iç model tahmini yapılmıştır. Her bir gizli değişkenin değeri kendisini oluşturan ölçüm değişkenlerinin ağırlıklı ortalaması olarak hesaplanır.

$$
\hat{\xi}_{j}=\sum \widetilde{w}_{j h} x_{j h}
$$

Yapısal eşitlik modellerinde değerleri bilinen gizli değişkenler arası ilişkiler basit veya çoklu regresyon yöntemiyle hesaplanırlar. Bu çalışmadaki modelde de her bir endojen gizli değişkenin ( ) tahmini için ayrı bir regresyon modeli kurulur. Teorik model 4 gizli değişkeni tahmin eden 4 farklı ilişki modelinden oluşmaktadır. Şekil 2'deki nedensonuç diyagramı modeldeki yapısal model ilişkileri hakkında bilgi vermektedir. Gizli değişkenler arasındaki okların üzerinde regresyon katsayıları ve anlamlılık seviyeleri ( $\mathrm{p}$ değeri) verilmiştir. Dairenin içinde değişken isimlerinin altındaki değerler ise R-kare değerleridir. R-kare değeri bağımlı değişkendeki değişimin (varyans) kendini tanımlayan model tarafından açılanabilme kapasitesini göstermektedir.

\section{Tablo 4}

Blokların komunaliti değerleri ve diğer bloklarla olan korelasyon kareleri

\begin{tabular}{|l|c|c|c|c|c|}
\hline Blok & ÇYK & IS & IAN & ITD & PRA \\
\hline ÇYK & $\mathbf{0 , 6 2 1 1}$ & 0,1316 & 0,1645 & 0,4559 & 0,3151 \\
\hline IS & 0,1316 & $\mathbf{0 , 7 9 6 6}$ & 0,3294 & 0,2507 & 0,0691 \\
\hline IAN & 0,1645 & 0,3294 & $\mathbf{0 , 8 0 4 3}$ & 0,3226 & 0,1679 \\
\hline ITD & 0,4559 & 0,2507 & 0,3226 & $\mathbf{0 , 6 4 0 0}$ & 0,3935 \\
\hline PRA & 0,3151 & 0,0691 & 0,1679 & 0,3935 & $\mathbf{0 , 7 1 3 7}$ \\
\hline
\end{tabular}




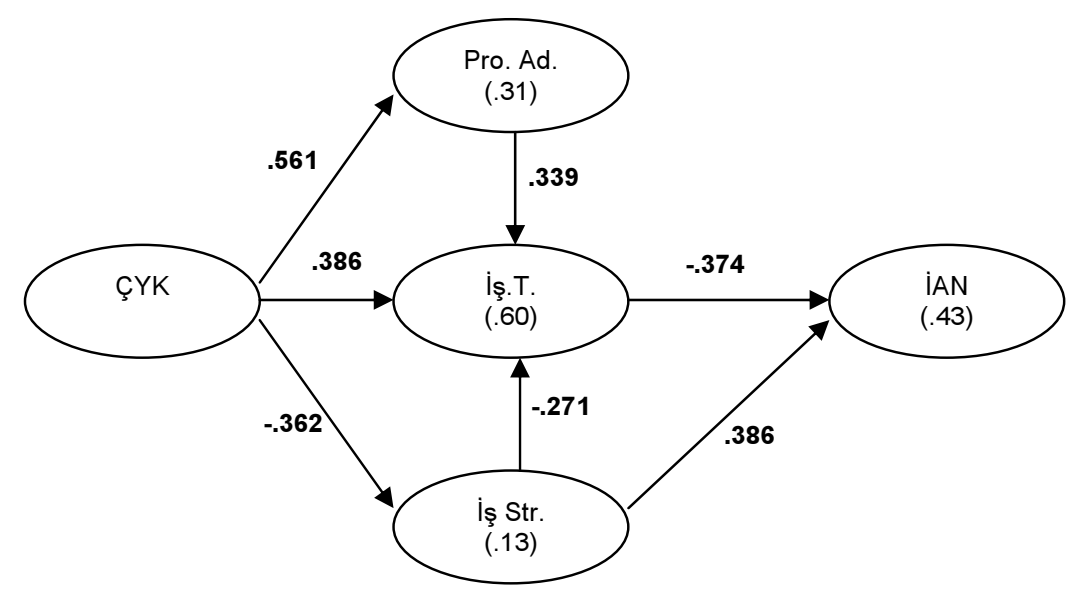

Şekil 2.

İç model sonuçları

(tüm regresyon katsayıları için $\mathrm{p}<0,001^{\prime}$ dir).
Modeldeki tüm ilişkilerin anlamlı olduğu gözükmektedir $(\mathrm{p}<0.001)$. Prosedür adaleti bloğuna etki eden çalışma yaşam kalitesinin ilişki katsayısı 0,56 olup modelin R-kare değeri 0,31 olarak bulunmuştur. Çalışma yaşam kalitesi ile iş stresi arasında negatif bir ilişki bulunmuştur $(-0,36)$. İş Tatmini bloğuna en fazla etki eden değişkenin Çalışma Yaşam kalitesi olduğu gözükmektedir $(0,386)$. Prosedür adaletinin de iş tatmini üzerinde önemli bir pozitif etkisi gözlemle-

\section{Tablo 5}

Hipotez Sonuçları

\begin{tabular}{|l|l|l|l|}
\hline S. & Hipotez & Hipotez Açıklaması & Sonuç \\
\hline 1 & H1 & ÇYK $\rightarrow$ PRA & KABUL \\
\hline 2 & H2 & ÇYK $\rightarrow$ İS & KABUL \\
\hline 3 & H3 & ÇYK $\rightarrow$ IT & KABUL \\
\hline 4 & H4 & PRA $\rightarrow$ İT & KABUL \\
\hline 5 & H5 & IS $\rightarrow$ IT & KABUL \\
\hline 6 & H6 & IT $\rightarrow$ İAN & KABUL \\
\hline 7 & H7 & IS $\rightarrow$ İAN & KABUL \\
\hline
\end{tabular}

nirken $(0,34)$, iş stresinin iş tatminine negatif yönlü etki ettiği bulunmuştur ($0,27)$. İş tatmini bloğunu tahmin eden modelin Rkare değeri $0.60^{\prime}$ dır. İşten ayrılma niyetine etki eden iki değişkenden iş stresinin ilişki katsayısı pozitif $(0,386)$, iş tatmininin ise negatiftir $(-0,37)$. İş stresinin çok yaşandığ 1 örgütlerde işten ayrilmaya olan niyet artarken, iş tatmini işten ayrılma niyetini düşürücü etkide bulunmaktadır. Bu değerlendirmeler sonucunda hipotez sonuçlarına ilişkin veriler Tablo 5'de görülmektedir.

\section{Sonuç ve Değerlendirme}

Geçmişten günümüze örgütsel verimliliğin arttırılmasında insan unsuru üzerinde yap1lan çalışmaların sayısı ve kapsamı giderek artmaktadır. Bu çalıșmalarda motivasyon faktörünün önemli bir rolü bulunmaktadır. Motivasyon faktörü, yazında farklı şekillerde tanımlanmakta ve kullanılmaktadır. Çalışma yaşamının kalitesi motivasyonun sağlanmasında, işgücünün verimliliğinin arttırılmasında ve nitelikli işgücünün örgütte tutulmasında önemli yere sahiptir. Nitekim motivasyonun çalışma yaşamına adaptasyonunda evrensel bir modele ulaşmak mümkün görülmemektedir. Çalışma yaşamı kalitesi kavramı bu araştırmalarda önemli bir kalıp arayışının sonuçlarından birisidir.

Çalışma yaşamı kalitesi ile pek çok örgütsel değişken arasında ilişki bulunmaktadır. Bu değişkenlerle ÇYK'nın birlikte kullanıldı̆̆ 1 optimum modeli belirlemek bu çalışmanın temel sorunsalıdır. Bu çerçevede çalışmada; bireysel ve örgütsel performansın arttırılmasında önemli bir yere sahip olan çalışma 
yaşamı kalitesinin çalışanların prosedür adaleti, iş stresi, iş tatmini ve işten ayrılma niyetine etkilerini belirlemek maksadıyla bir model geliştirilmiş ve bu model ile modele ilişkin hipotezler yapısal eşitlik modeli içerisinde test edilmiştir.

Araştırma sonucunda, çalışma yaşamı kalitesi çalışanların prosedür adaleti algısını pozitif ve anlamlı olarak etkiler hipotezi (H1) beklenildiği gibi kabul edilmiştir. Aynı şekilde Fryxell ve Gordon (1989) ve Yoon'un (1996) çalışmalarıyla paralel olarak prosedür adaleti çalışanların iş tatmini algısını pozitif ve anlamlı olarak etkiler (H4) hipotezi de kabul edilmiştir. Çalışma yaşamı kalitesinin çalışanların iş stresini anlamlı ve negatif olarak etkilediği bulunmuş ve (H2) hipotezi kabul edilmiştir. Bu sonuç, Babin ve Boles (1998), Sullivan ve Baghat (1992), Jackson ve Schuler (1985) ve Daniels ve Bailey (1999)'in çalışmalarıyla benzer sonuçlar ortaya koymuştur. Çalışma yaşamı kalitesinin çalışanların iş tatminini pozitif ve anlamlı olarak etkilediği yönündeki hipotez (H3) kabul edilerek, Fields ve Thacker (1992) ve Kawai ve Wyatt (2007)'ın bulgularına paralel sonuçlara ulaşılmıştır. İş stresi ile iş tatminini ilişkisini belirlemeye yönelik oluşturulan $\mathrm{H} 5$ hipotezi, Judge ve Colquitt (2004) ve Mohr vd. (2007) tarafından yapılan çalışmalarla benzer sonuçlar ortaya koymuş ve kabul edilmiştir. İAN ile ilgili olarak oluşturulan İş tatmini- İAN (H6) hipotezi Dreher (1982), Carter vd. (1990), Efraty ve Sirgy (1990) ve Efraty vd. (1991)'ın çalışmaları ile uyumlu sonuç vermiş ve kabul edilmiştir. İş stresi İAN ilişkisini ortaya koyan H7 hipotezi de Matteson ve Ivancevich (1987) ile benzer sonuçlar ortaya koymuş ve kabul edilmiştir. Araştırma kapsamında ortaya konulan hipotezlerin tamaminın kabul edilmesi, ortaya konulan modelin uyumluluğu konusunda bizlere önemli bir fikir vermektedir.

Bir yapısal eşitlik modelinin kabul edilebilirliği bulunan sonuçların güvenilirliği ve geçerliliğine bağlıdır. Bu çalışmada önerilen yapısal eşitlik modelinin güvenilirlik ve geçerlilikleri; modelin tek boyutluluk analizi, madde güvenilirliği, yakınsaklık geçerliliği ve blokların ayırt edicilik analizleri ile test edilmiştir. Tüm bu sonuçlar tatmin edici olarak bulunmuştur. KEKK modelinin öncelikli amacı tüm bağımlı değişkenlerdeki açıklanan hatanın minimizasyonu (veya açıklanan varyansın maksimizasyonu) olduğundan iç modellerin R-kare değerleri de diğer bir model iyilik sonucu olarak kullanılmıştır. RKare değeri iş tatmini için 0,60; işten ayrılma niyeti için ise 0,43 olarak bulunmuştur. Modelde önerilen tüm ilişkilerin anlamlı olması da $(p<0.001)$ kurulan hipotezlerin doğrulandığının göstergesidir.

Tüm bu bulgulara rağmen araştırmanın bazı kısıtları da bulunmaktadır. Araştırmanın en önemli kısıdı örneklemin üniversite öğretim elemanları ile sınırlı olmasıdır. Bu nedenle bulguların genellenebilmesi için benzer çalışmaların, farklı örneklemlerde tekrar edilmesi gerekir. Çalışma sonucunda, üzerinde yazında yeterli miktarda çalışma olmayan ÇYK ve ÇYK ile ilişkili olduğu düşünülen diğer değişkenler arasındaki ilişki araştırılmiştır. Ayrıca araştırma metodunun yeni bir metot olmasının (KEKK) araştırmacılar için

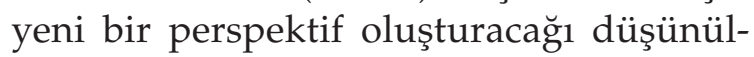
mektedir. Bundan sonra yapılacak çalışmalarda araştırmacılara modelin farklı değişkenlerle geliştirilmesi önerilebilir. Bu kapsamda örgütsel adaletin diğer boyutlarına da araştırılacak modellerde yer verilmesinin önemli bir açılım olacağ 1 değerlendirilmektedir. 


\section{KAYNAKÇA}

Adams, J. (1965), Inequity in Social Exchange, in L Berkowitz (Ed.), Advances in Experimental Social Psychology, Academic Press, New York London, Vol.2,P. 267-299.

Adams, J.S. (1963). Toward An Understanding of Inequity. Journal of Abnormal and Social Psychology, 67, 422-436.

Arnold, J., ve Feldman, D. (1986). Organizational behavior. New York: MCGrawHill.

Babin, B., Boles J. (1998) Employee Behavior in A Service Environment: A Model and Test of Potential Differences Between Men and Women. Journal of Mark, 62: 77-91.

Bollen, K.A. (1989). Structural Equations With Latent Variables, Wiley, New York.

Boyett, J.H. ve Boyett J.T., (1999). Four Essentials for Motivating Employees in A Changing Environment, Innovative Leader, 8, 10.

Carter, C., Pounder, F., Lawrence, F. ve Wozniak, P. (1990) Factors Related Organizational Turnover Intentions of Louisiana Extension Service Agents, in: H. Meadow ve M. Sirgy (Eds), Qualityof-Life Studies in Marketing and Management :170-181 (Blacksburg, Va: International Society for Quality-of-Life Studies).

Chang, E. (2002). Distributive Justice and Organizational Commitment Revisited: Moderation By Layoff in The Case of Korean Employees, Human Resource Management, Vol. 41, No. 2.
Chin, W.W. (1998). The Partial Least Squares Approach for Structural Equation Modeling, in Marcoulides G.A. Ed., Modern Methods for Business Research, Lawrence Erlbaum Associates, 295-336, New Jersey.

Cicero, L. ve Pierro, A. (2007). Charismatic leadership and organizational outcomes: The mediating role of employees' work-group identification, International Journal of Psychology, Vol. 42 Issue 5, ss.297-306.

Cohen, S. (1997). A Hierarchical Construct of Self-Management Leadership and Its Relationship to Quality of Work Life and Perceived Work Group Effectiveness. Personnel Psychology, 50, 275-308.

Colquitt, J.A. (2001)."On the dimensionality of organizational justice: a construct validation of a measure". Journal of Applied Psychology, 86, 386-400.

Creech, R., (1995). Employee Motivation, Management Quarterly, 362.

Cropanzano, R., ve Greenberg, J. (1997). Progress in Organizational Justice: Tunneling Through The Maze. In Cooper, C. L., and Robertson, I. T. (Eds.), International Review of Industrial and Organizational Psychology, Wiley, New York: 317-372.

Çekmecelioğlu, H. G. (2005). Örgüt ikliminin iş tatmini ve işten ayrılma niyeti üzerindeki etkisi : Bir araştırma", Cumhuriyet Üniversitesi İktisadi ve İdari Bilimler Fakültesi Dergisi, Cilt: 6, No:2.

Daniels K, Bailey A. (1999). Strategy Development Processes and Participation in Decision Making: Predictors of Role Stressors and Job Satisfaction. J. of Applied Management Studies; 8: 27- 42. 
Davis, A. ve Cherns, B. (1975). The Quality of Working Life. Volume 1: Problems, Prospects and The State of The Art, The Free Pres, New York,

Davis, K., (1981). Human Behavior At Work: Organizational Behavior, Mcgraw Hill, USA.

Davis, L. ve Cherns, A. (1975). The Quality of Working Life (New York: Free Press).

Davis, L.E., Levine, M.F. ve Taylor, J.C. (1984) Defining Quality of Working Life, Human Relations, 37, 1: 81-104.

Dreher, G. F. (1982). The Role of Performance in The Turnover Process, The Academy of Management Journal, 25,1: 137-174.

Efraty, D. ve Sirgy, M. (1990). The Effects of Quality of Working Life (QWL) On Employee Behavioural Responses, Social Indicators Research, 22, 1: 31-47.

Efraty, D., Sirgy,M. ve Claiborne, C. B. (1991). The Effects of Personal Alienation On Organizational Identification: A Quality-of-Work Life Model, Journal of Business and Psychology, 6(1), ss. 57-78.

Fields, M.W., Thacker, J. W. (1992). Influence of Quality of Work Life on Company and Union Commitment, Academy of Management Journal, Vol. 35, No. 2, 439-450.

Folger, R. ve Konovsky, M.A. (1989). Effects of Procedural and Distributive Justice On Reaction to Pay Raise Decisions, Academy of Management Joumal, 32: $115-30$

Fornell, C. and Bookstein, F.L. (1982). Two Structural Equation Models: Lisrel and PLS Applied to Consumer Exit-Voice Theory, Journal of Marketing Research, 19, 4: 13
Fryxell, G. E., ve Gordon, M. E. (1989). Workplace Justice and Job Satisfaction as Predictors of Satisfaction With Union and Management. Academy of Management Journal, 32, 851-866.

Fryxell, G.E. ve Gordon, M.E. (1989). Workplace Justice and Job Satisfaction As Predictors With Unions and Management, Academy of Management Joumal, 32: 851-66.

Ganster, D. C. ve Schaubroeck, J. (1991). Work Stress and Employee Health, Journal of Management, 17, 2.

Gefen, D., Straub W. D. ve Boudreau M.C. (2000). Structural Equation Modelling and Regression: Guidlines for Research Practice, Communications of The Association for Information Systems, 4 , 7: 180

Greenberg, J. (1987). A Taxonomy of Organizational Justice Theories. Academy of Management Journal, 12, 1: 9-22.

Greenberg, J. (1990). Looking Fair Vs Being Fair: Managing Impressions of Organizational Justice, in Staw, B.M., Cummings, L.L. (Eds), Research in Organizational Behavior, Ja1 Press, Greenwich, Ct, Vol. 12 ss.111-57.

Gürpınar, G. (2006), An Empirical Study of Relationships Among Organizational Justice, Organizational Commitment, Leader-Member Exchange, and Turnover Intention, Yayımlanmamış Yüksek Lisans Tezi, Yeditepe Üniversitesi, İstanbul.

Hackman, J. ve Suttle, J. (1977). Improving Life At Work (Glenview, Il: Scott- Foresman).

Hom, P. W. ve Griffeth, R. W. (1995). Employee Turnover. Cincinnati, Oh: Southwestern. 
Hulland, J.s. (1999). Use of Partial Least Squares (Pls) in Strategic Management Research: A Review of Four Recent Studies, Strategic Management Journal, 20, 2, 195-204.

Huzzard, T. (2003). The Convergence of The Quality of Working Life and Competitiveness, National Institute for Working Life, Stockholm.

İşbaşı, J.Ö.(2000). Çalışanların Yöneticilerine Duydukları Güvenin Ve Örgütsel Adalete İlişkin Algılamalarının Vatandaşlık Davranışının Oluşumundaki Rolü:Bir Turizm Örgütünde Uygulama, Yayımlamamış Yüksek Lisans Tezi, Akdeniz Üniversitesi SBE.

Jackson, S, Schuler, R. A. (1985). MetaAnalysis and Conceptual Critique of Research On Role Ambiguity and Role Conflict in Work Settings. Organizational Behavior Human Decision Processes; 36:16- 78 .

Judge, T. A. ve Colquitt, J. A. (2004). Organizational Justice and Stres: The Mediating Role of Work- Family Conflict, Journal of Applied Psychology, Vol. 89, No: III, ss.395-404.

Kabanoff, B. (1980). Work and Non-Work: A Review of Models, Methods and Findings, Psychological Bulletin, 88: 60-77.

Kahn, R. (1981). Work and Health (New York: John Wiley).

Kemery, E, Bedeian A, Mossholder K, Touliatos J. (1985). Outcomes of Role Stress: A Multisample Constructive Replication. Acadamy of Management Journal, 28:363- 75 .

Kovach, K.A. (1995). Employee Motivation: Addressing A Crucial Factor in
Küçükusta, D. (2007), Konaklama İşletmelerinde İş-Yaşam Dengesinin Çalışma Yaşamı Kalitesi Üzerindeki Etkisi, Yayımlanmamış Doktora Tezi, İzmir.

Larkin, J. M. (1995). Managing Employee Turnover is Everyone's Business. National Public Accountant, 40 (9), 34-36.

Lawler, E. (1982) Strategies for Improving The Quality of Work Life, American Psychologist, 37: 66-73.

Lawler, E. E. (1975). Measuring The Psychological Quality of Working Life: The Why and How of It, L. E.

Lovio-George, C., (1992). What Motivates Best?, Sales and Marketing Management, 144, 4 .

Lowe, R. H. ve Vondanovich, S. J. (1995). A Field Study of Distributive and Procedural Justice as Predictors of Satisfactiion and Organizational Commitment, Preview Journal of Business \& Psychology, Vol. 10 Issue 1, ss. 99-114.

Matteson, M ve Ivancevich, J. (1987). Controlling Work Stress. London: JosseyBass.

May, B. E., Lau, R. S. M., ve Johnson, S. K. (1999). A Longitudinal Study of Quality of Work Life and Business Performance. South Dakota Business Review, 58 (2), 37.

Medcof, J.W. ve Hausdorf P.A., (1995). Instruments to Measure Opportunities to Satisfy Needs and Degree of Satisfaction of Needs in The Workplace, Journal of Occupation and Organizatinal Psychology, 683.

Miller, K.I., ve Monge, P.R. (1986). Participation, Satisfaction and Productivity: A Meta-Analytic Review, Academy of Management Reviev, 29: 727-753. 
Mohr, A. T. ve Puck J. F., Role Conflict, General Manager Job Satisfaction and Stress and the Performance of IJVs,

European Management Journal, Volume 25, Issue 1, ss. 25-35.

Moorman, R. H. (1993). The Influence of Cognitive and Affective Based Job Satisfaction Measures on the Relationship Between Satisfaction and Organizational Citizenship Behavior. Human Relations, 46/6, ss. 759-776.

Moorman, R.H. (1991). Relationship Between Organizational Justice and Organizational Citizenship Behaviors: Do Fairness Perceptions Influence Employee Citizenship?, Journal Of Applied Psycho$\log y, 76,6$.

Near, J., Rice, R. ve Hunt, R. (1980) The Relationship Between Work and Nonwork Domains: A Review of Empirical Research, Academy of Management Review, 5, ss. 415-429.

Niehoff, R.T., Moorman, R.H, (1993). Justice As A Mediator of The Relationship Betweenmethods of Monitoring and Organizational Citizenship Behavior, Academy of Management Journal, 36.

Oran, B., N. (1989). Job Satisfaction of a Group of Academic Staff in Marmara University, (Yayımlanmamış Yüksek Lisans Tezi) (İstanbul: Marmara Üniversitesi).

Özdevecioğlu, M. (2003). Algılanan Örgütsel Adaletin Bireyler Arası Saldırgan Davranışlar Üzerindeki Etkilerinin Belirlenmesine Yönelik Bir Araştırma, Erciyes Üniversitesi İktisadi ve İdari Bilimler Fakültesi Dergisi, Sayı: 21: 77-96.
Özyurda, M. (1994). Endüstriyel İsletmelerde Verimlilik ve Metal İşkolunda Çalışanların Verimlilikleri ile Çalışma Hayatının Kalitesinin İlişkilendirilmesi, Gazi Üniversitesi, Sosyal Bilimler Enstitüsü Yayınlanmamış Doktora Tezi, Ankara: 89-90.

Pars, F. ve Şive, O.Ç. (1996), İş Yerinde Motivasyon, Human Resources: İnsan Kaynakları ve Yönetim Dergisi, 1, 2.

Porter, L.W., Steers, R.M., Mowday, R.T. ve Boulian, P.V. (1974). Organizational Commitment, Job Satisfaction, and Turnover Among Psychiatric Technicians, Joumal of Applied Psychology, 59: 603609.

Quinn, R. ve Shephard, I. (1974) The 19721973 Quality of Employment Survey (Ann Arbor, MI: Institute for Social Research, University of Michigan).

Rigdon, E.E. (1998). Structural Equation Modeling, in Marcoulides G., Ed, Modern Methods for Business Research, Lawrence Erlbaum, 251-94, New Jersey.

Roth, P. G., ve Roth, P. L. (1995). Reduce Turnover With Realistic Job Previews. Cpa Journal, 65 (9),

Sabuncuoğlu, Z. ve Tüz, M., (2001). Örgütsel Psikoloji, 4.Baskı, Ezgi Kitabevi, Bursa.

Sharpley, C. F., Reynolds, R., Acosta, A. ve Dua, J. K. (1996). The Presence, Nature and Effects of Job Stress On Physical and Psychological Health At A Large Australian University. Journal of Educational Administration, 34(4).

Shaw, J.D., Delery, J.E., Jenkins, G.D. Jr. ve Gupta, N. (1998). An OrganizationLevel Analysis of Voluntary and Involuntary Turnover. Academy of Management Journal, 41 (5), 511-525. 
Sirgy, M. J., Efraty, D., Siegel, P. ve Lee, D. J. (2001). A New Measure of Quality of Work Life (QWL): Based on Need Satisfaction and Spillover Theories, Social Indicators Research, Vol.55, No.3, , ss. 241-302.

Staines, G. (1980) .Spillover Versus Compensation: A Review of The Literature On The Relationship Between Work and Nonwork, Human Relations, 33, ss. 111129.

Steers, R.M. ve Porter, L.W. (1983). Employee Commitment to Organizations. In R. M. Steers ve L. W. Porter (Eds.), Motivation and Work Behavior (3d Ed.): 441-451. Mccraw-Hill.

Sullivan, SE, Baghat, R.S. (1992). Organizational Stress, Job Satisfaction, and Job Performance: Where Do We Go From Here?, Journal of Management, 18: 353375 .

Sweeney, P. D. ve McFarlin D. B. (1997). Process and outcome: Gender differences in the assessment of justice. Journal of Organizational Behavior, 18, 83-98

Şimşek, Ö. F. (2007). Yapısal Eşitlik Modellemesine Giriş: Temel İlkeler ve Lisrel Uygulamaları, Ekinoks, Ankara.

Tenenhaus, M., Vinzi, V.E., Chatelin, Y.M. ve Lauro, C., (2005). Pls Path Modeling, Computational Statistics and Data Analysis, 48, 159-205.

Tetrick, L.E, ve Larocco J. M. (1987). Understanding, Predicting, and Control As Moderators of The Relationships Between Perceived Stress, Satisfaction and Psychological Well-Being. J. of Appl. Psychology, 72: 538- 43.

Thibaut, J. W. ve Walker, L. (1975). Procedural Justice: A Psychological Analysis. Hillsdale, NJ: Erlbaum.
Tuten, T. L. ve Neidermeyer. P. E. (2004). Performance, Satisfaction and Turnover in Call The effects of Stress and Optimism, Journal of Business Research, 57 26-34

Voki , N. P. ve Bogdani , A. (2007). Individual Differences and Occupational Stress Perceived: A Croatian Survey. Working Paper Series.

Walton, R. E. (1975). The Diffusion of New Work Structures:Explaining Why Success Didn't Take, Organizational Dynamics, ss.3-22.

Walton, R. E. (1985), From Control to Commitment in The Work Place. Harvard Business Review, 63(2): 77-84.

Wayne, S.J., Shore L. M. ve Linden R. C., (1997), Perceived Organizational Support and Leader Member Exchange: A Social Exchange Perspective, Academy of Management Journal, 40: 82-111.

Weiss, D. J., Dawis, R. V., England, G. W.ve Lofquist, L.H. (1967). Manual for the Minnesota Satisfaction Questionnaire. Industrial Relations Center, University of Minnesota. -

Williams, E., Konrad, T., Scheckler, W. ve Pathman, D. (2001). Understanding Physicians' Intentions to Withdraw From Practice: The Role of Job Satisfaction, Job Stress, Mental and Physical Health. Health Care Manage Rev, 26: 7- 19.

Wold, H., (1985). Partial Least Squares, in Kotz, s. ve Johnson, N.L., Eds, Encyclopedia of Statistical Sciences, Wiley, New York: 581-591.

Yıldırım, F. (1996). Banka Çalışanlarında Algılanan Rol Çatışması ve Belirsizliği ve İş Doyumu İle Tükenmişlik Arasındaki İlişki (Yayınlanmamış Yüksek Lisans Tezi) (Ankara: Hacettepe Üniversitesi Sosyal Bilimler Enstitüsü). 
Yoon, J. (1996). Fairness Issues and Job Satisfaction Among Korean Employees: The Significance of Status Value and Procedural Justice in Work Orientation. Social Justice Research (9) 2: 121-43.

Young, K ve Couper G. (1995). Occupational Stress in The Ambulance Service: A Diagnostic Study. J Manage Psychol;10: 29 -36 .

Your Organization's Performance, Employee Relations Today, (22) 2, ss. 93-105. 